\title{
Influence of Socioeconomic Status on Oral Disease Burden: A Population-Based Study
}

Edson Hilan Gomes de Lucena ( $\nabla$ edson.lucena@academico.ufpb.br )

Universidade Federal da Paraiba https://orcid.org/0000-0003-3431-115X

\section{Rênnis Silva}

Universidade Federal da Paraiba

Maria Barbosa

Universidade Federal da Paraiba

\section{Elza Araújo}

Universidade Federal da Paraiba

\section{Antônio Pereira}

Universidade Estadual de Campinas

\section{Yuri Cavalcanti}

Universidade Federal da Paraiba

\section{Research article}

Keywords: Oral Health, Global Burden of Disease, Socioeconomic Factors

Posted Date: July 16th, 2020

DOl: https://doi.org/10.21203/rs.3.rs-41112/v1

License: (c) (i) This work is licensed under a Creative Commons Attribution 4.0 International License.

Read Full License 
1 Influence of socioeconomic status on oral disease burden: a population-

2

3

4

5

6

7

8

9 based study

\section{ABSTRACT}

Background: Dental caries is associated with Biological, behavioral, socioeconomic, and environmental factors; however, socioeconomic status is a distal determinant of dental caries development that modulates exposure to risk and protective factors. This study aimed to analyze the factors associated with the distribution and concentration of oral diseases in a population-based study in Brazil. Methods: This is a quantitative, analytical, cross-sectional study based on secondary data from the SB São Paulo 2015 epidemiological survey. A total of 17,560 subjects were included. The concentration of oral disease in the population was estimated by the oral disease burden (ODB) variable. The ODB consists of four components: dental caries; tooth loss; need for dental prosthesis and periodontal condition. Thus, the total score on the ODB could vary between 0 and 4 , with the highest score indicating the worst possible situation. ODB was analyzed in multivariate negative binomial regression, and multivariate binary logistic regression analysis. The following demographic data were included as independent variables: age group, skin color, socioeconomic data, and family income. Results: ODB was present in $86.9 \%$ of the sample. Negative multivariate binomial regression showed a statistically significant relationship $(p<0.005)$ between ODB and all variables analyzed (skin color, family income, education, OIDP results and age range). The adjusted multivariate binary logistic regression showed that the individuals most likely to have at least one component of ODB were nonwhite (25.5\%), had a family income of up to $R \$ 1,500.00$ / month (19.6\%), had only completed primary education 
27 (19.1\%), and reported that their oral health had an impact on their daily activities

28 (57.6\%). Elderly individuals were two times more likely than adolescents to have an

29 ODB component. Conclusions: ODB is associated with factors related to social

30 inequality. Adults and elderly individuals had the highest cumulative number of ODB

31 components.

32 Keywords: Oral Health; Global Burden of Disease; Socioeconomic Factors. 


\section{BACKGROUND}

Oral diseases are a major global public health problem with a high prevalence and large negative impacts on individuals, communities, and society. These diseases disproportionately affect the poorest and most marginalized groups in society and are closely linked to socioeconomic status and social determinants of health [1].

Biological, behavioral, socioeconomic, and environmental factors are associated with dental caries and its consequences [2]. Socioeconomic status is a distal determinant of dental caries development that modulates exposure to risk and protective factors as well as access to oral health services [3]. These inequalities in the distribution of dental caries have been reported in different countries $[4,5]$. In this context, the World Health Organization (WHO) determined that studies on socioeconomic inequalities in the distribution of oral diseases and on the design of strategies to increase access should be research priorities for the 21st century [6].

To provide greater equity in dental care for socially disadvantaged groups, it is necessary to understand populations' specific characteristics, their socioeconomic status, and, above all, the influence of these factors on their healthrelated behavior. Such understanding will contribute to reducing disparities in oral health $[7,8]$. There is an urgent need for appropriate actions and services to effectively address disparities in the oral health of disadvantaged groups [9].

The use of information on the living conditions of the population is essential given the need to ensure that the provision of health care is guided by equity. This information should underpin analyses of the health-disease status of the population in each territory and should inform the planning and development of actions aimed at those who need them the most. That is, the information must be used to inform 
58 the action, and the actions must be equitable [10].

For the institutionalization of a health surveillance model, as expected by the Brazilian Unified Health System (Sistema Único de Saúde, SUS), accurate epidemiological information is necessary because it indicates profiles and trends in health conditions [11]. Based on this premise, it is expected that dentists working in primary health care will have the information and knowledge about the population in the territory under their care that is necessary to strengthen and direct their actions towards those who most need them [12].

With the objective of eliminating inequalities caused by adverse social conditions, the SUS advocates equity [13]. Universal health care systems offer an opportunity for dental health services to become more integrated into the broader health care system and to be more accessible and meet the oral health needs of the population [14].

Socioeconomic status is historically associated with inequalities in oral health [1,15-17]. However, socioeconomic factors related to the prevalence and severity of oral diseases in portions of the population still need to be elucidated. Identifying which factors are decisive in the concentration of diseases within the population can help health care managers and health professionals to intervene more efficiently and equitably. To this end, this study aimed to analyze the factors associated with the distribution and concentration of oral diseases in a population-based study in Brazil.

\section{METHODS}

This is a quantitative, analytical, cross-sectional study based on secondary data from the SB São Paulo 2015 (SBSP-2015) epidemiological survey. The data 
83

84

85

86

87

88

89

90

used in this study were extracted from the public dataset of the study, which is available online [18].

The SBSP-2015 was a population-based study that aimed to evaluate population-based oral health and socioeconomic status in different age groups in the state of São Paulo, Brazil. The complex sample was divided into the six domains of the state (including the capital, the metropolitan region of São Paulo and 15 Regional Health Districts). A two-stage selection process with a selection probability proportional to the population size was used in the sampling design: 1) 178 cities, including the capital São Paulo, were designated primary stage units (PSAs), and 2) two census tracts were randomly selected in each selected city (secondary stage units, SSUs, totaling 390 areas), including 36 areas within São Paulo state. Data relative to the age groups of 15 to 19 years $(n=5,585), 35$ to 44 years $(n=6,051)$ and 65 to 74 years $(n=5,951)$ were used, and a total of 17,560 subjects were included.

Examiner training procedures, data collection methods and the variables included in the study were previously described in other studies [19-24]. The concentration of oral disease in the population was estimated by the oral disease burden (ODB) variable, which was the outcome of this study. The ODB variable consists of four components: dental caries; tooth loss; need for dental prosthesis and periodontal condition (gingival bleeding, tartar and periodontal pocketing), which are categorized as "0" (absence of the condition) or "1" (presence of the condition). Thus, the total score on the ODB could vary between 0 and 4 , with the highest score indicating the worst possible situation since it indicated that the subject presented all the evaluated conditions. 
108 regression, in which it was categorized according to five levels: 0 indicated the absence of all components of ODB, 1 indicated the presence of one of the components, 2 indicated the presence of two components, 3 indicated the presence of three components, and 4 indicated the presence of all components of ODB. The second method was multivariate binary logistic regression analysis, in which the variable was dichotomized as "no ODB" (the absence of the evaluated indicators) and "ODB" (the presence of at least one evaluated indicator). The following demographic data were included as independent variables: age group, subdivided into "adolescents" (15 to 19 years old), "adults" (35 to 44 years 117 old), and "elderly" (65-74 years old); skin color, dichotomized as "white" and 118 "nonwhite"; and socioeconomic data, including education, which was dichotomized as "primary education" and "secondary or higher education", and family income, which was dichotomized as "up to $\mathrm{R} \$ 1,500.00 /$ month" and "over

$121 \mathrm{R} \$ 1,500.00 /$ month". The Oral Impact on Daily Performance (OIDP) scale score was 122 dichotomized as "impact" for people who answered "yes" to one or more questions and "no impact" for participants who answered "no" to all 9 questions on the questionnaire, which was used to assess quality of life through the impact of oral health on daily living [25-26].

Analyses were performed using the Statistical Package for Social Sciences (IBM-SPSS, v.24, IBM, Chicago, IL) software considering a 95\% confidence interval and a statistical significance of $5 \%$. ODB fit a negative binomial distribution, and a negative binomial multiple regression analysis was performed. All independent variables were included in the negative binomial multiple regression model. To

131 adjust the model, variables with $p$-values $>0.20$ were removed. From the 132 coefficients of the negative binomial regression model, the effect magnitudes were 
133

134

135

136

137

138

139

140

141

142

143

144

145

146

147

148

149

150

151

152

153

154

155

156

157

estimated by using prevalence ratios (PR) and 95\% confidence intervals.

After the adjusted negative binomial regression model was obtained, the dependent variable (ODB) was dichotomized and analyzed according to a binary logistic regression model to determine the effect of the independent variables included in the adjusted model on the chance of an individual having ODB $\geq 1$. For this purpose, odds ratios (OR) and 95\% confidence intervals were estimated. Then, multiple correspondence analysis (MCA) was performed to determine the interaction/proximity of each independent variable category with the possible outcomes of the dependent variable (the presence and absence of ODB) [27]. The MCA resulted in a contingency diagram that enabled a qualitative analysis of the effect of the interaction between the independent and dependent variables to complement the multivariate logistic regression.

The SBSP-2015 study was approved by the Human Research Ethics Committee of the School of Dentistry of Piracicaba (FOP-UNICAMP) and registered under number 1,211,025; CAEE no. 46788215.9.0000.5418. Everyone who participated in the study signed an informed consent form.

\section{RESULTS}

ODB was present in $86.9 \%$ of the sample $(n=17,560)$, which consisted of $31.7 \%$ adolescents, $34.5 \%$ adults, and $33.9 \%$ elderly individuals. Of these, $63.6 \%$ were self-reported as nonwhite, $45.5 \%$ had a family income greater than $\mathrm{R} \$ 1,501.00 /$ month, $54.4 \%$ had completed primary education, and $56.6 \%$ of the sample indicated that their oral health had an impact on their daily activities, as evaluated by the OIDP (Table 1).

Negative multivariate binomial regression showed a statistically significant 
158 relationship $(p<0.005)$ between ODB and all variables analyzed (skin color, family

159 income, education, OIDP results and age range) (Table 2). The highest frequency

160 of ODB components was observed in nonwhite individuals (8.4\%) with a family

161 income of up to $\mathrm{R} \$ 1,500.00 /$ month $(7.8 \%)$, those who had only completed primary

162 education (16.1\%), and those who indicated that their oral health had an impact on

163 their daily activities (25.8\%). Elderly individuals (65 to 74 years old) and adults (35

164 to 44 years old) were more likely than adolescents (15 to 19 years old) to have an

165 additional ODB component.

166 The adjusted multivariate binary logistic regression showed that the

167 individuals most likely to have at least one component of ODB were nonwhite

168 (25.5\%), had a family income of up to $R \$ 1,500.00 /$ month (19.6\%), had only

169 completed primary education (19.1\%), and reported that their oral health had an

170 impact on their daily activities (57.6\%). Elderly individuals were two times more likely

171 than adolescents to have an ODB component (Table 3).

172 Multiple correspondence analysis was performed with all the independent 173 variables that were statistically significant in the multivariate binary logistic 174 regression analysis. Figure 1 shows a greater relationship/proximity between "No 175 oral health burden" and the characteristics "teenager", "white", "no impact of oral 176 health on daily activities", "family income over $\mathrm{R} \$ 1,500.00 /$ month" and "secondary 177 or higher education". 
179 


\section{DISCUSSION}

The results of this study reinforce the association between socioeconomic inequalities and the concentration of oral diseases. In addition, it highlights the need to examine access to public oral health services. The distribution of oral diseases occurs heterogeneously in different social groups. Oral disease is considered a health inequality, given that it is preventable, and the fact that it persists is unjust [28].

A greater presence of components of ODB (dental caries, tooth loss, the need for dental prostheses, and periodontal conditions) was identified in nonwhite individuals, those with a low family income, those with few years of study, and those who indicated that their oral health had an impact on their daily activities. This supports the findings of the study, who argue that strong socioeconomic inequalities in oral health mean that poor and vulnerable groups in society are particularly affected [14].

It is relevant to investigate whether the majority population group in Brazil (the brown and black population) is receiving adequate care to reduce the burden of oral diseases [29]. This group is more vulnerable because it has lower levels of education and income [30], poorer overall health outcomes [31] and poorer oral health [32]. However, although they are at higher risk, they are less likely to use the dental health services available [33] and to visit the dentist for preventative care [29].

The association of higher ODB with socioeconomic factors reinforces the need to overcome the exclusiveness of oral health care approaches and to combine broader policy initiatives to combat oral health inequalities at the structural level, with a focus on social issues, determinants of health and shared risk factors between 
205

206

207

208

209

210

211

212

213

214

215

216

217

218

219

220

221

222

223

224

225

226

227

228

229

oral diseases and other chronic noncommunicable diseases [34].

The few studies of this higher disease burden demonstrate the need for inclusive educational policies. Cities with better educational policies showed a lower prevalence of untreated dental caries and tooth loss than cities with worse educational policies [35]. Education can also act indirectly on income: the higher an individual's education level is, the greater his or her possibility of finding a better paid job, which would increase his or her ability to pay for private dental care, among other needs [29]. In addition, the positive impact can manifest as increased knowledge and the adoption of healthy habits [36].

The lower income group had higher percentages of untreated dental caries in all municipalities, regardless of the availability of public policies (sanitation, dental care and education) and the fluoridation of public water supply. The income indicator establishes a nexus with health levels to the extent that it enables individuals to acquire goods and services that promote or rehabilitate health [36].

The adjusted multivariate binary logistic regression model showed that elderly individuals have a two times greater chance than adolescents of having a component of ODB. This demonstrates that socioeconomic status cumulatively affects oral health throughout life and highlights the importance of this status as an indirect factor in oral health later in life [37].

In this study, we considered different age groups because it is necessary to expand oral health studies beyond children and adolescents to include adults and elderly individuals due to changes in the aging of the population, the increase in life expectancy, and the displacement of the disease burden in the direction of chronic diseases. For this reason, studies on inequalities in the distribution of dental caries among these groups are necessary [3]. 
The OIDP results were associated with a higher ODB. The analysis of this

231

232

indicator is relevant because it enables the assessment of oral health-related quality of life (HRQOL). Oral HRQOL is a multidimensional indicator that assesses the extent to which oral diseases affect the daily functioning and the social, emotional and psychological well-being of individuals [38]. The findings corroborate those of other studies that associate the worst individual social conditions with oral health problems and low HRQOL [39-41].

Considering the high concentration of goods and wealth in Brazil and the existence of a health system that includes equity as one of its principles, it is very important for health research and planning to have a systematic understanding of studies that have investigated social inequalities in the prevalence of dental caries [3].

The use of zone and population information in the planning and programming of health services is a major challenge given the initial limitation of professional training and the efforts required by the health surveillance-based model of care, which is based on the premise that information on determinants, risk and protective factors, and damage to health can be monitored to identify vulnerable groups and populations or those with potential for a healthy life [42].

There are compelling reasons to be concerned with resolving health inequalities. The persistence of differences in health based on race/ethnicity or other social factors (such as education) raises moral concerns and upsets the basic notion of justice and human rights.

The current study has some limitations and strengths. In general, this population-based study from the state of São Paulo provides some evidence of the social and economic factors associated with a greater ODB. Although it is not 
255 possible to replicate the results for the entire country of Brazil, it is noteworthy that 256 São Paulo is the most populous state in the country, comprising approximately $22 \%$ 257 of the Brazilian population [43].

258 It should be noted that the multiple correspondence analysis should be 259 interpreted as complementary to the logistic regression model because it illustrates 260 the relationships of each category of independent variable with the binary categories 261 of the dependent variable.

Due to the cross-sectional nature of the study, temporal relationships cannot be elucidated. However, the inverse cause may be unlikely given that the components of ODB have low latency in the population, presumably because the contextual characteristics that were evaluated, such as race/color and years of study, were present before the ODB emerged.

The findings of this study may help researchers, oral health professionals and managers in planning and programming oral health services in the SUS. Other studies that analyze the association between oral health diseases and socioeconomic factors, the work of oral health teams, and the organization of the

Oral Health Network are necessary to construct an inclusive and effective practice; therefore, it is necessary to approach the people who need oral health services and try to understand their living conditions.

\section{CONCLUSION} ODB is associated with factors related to social inequality. In the state of São

277 Paulo, higher ODB was present in those who had only completed primary school, are nonwhite, those with a low family income, and those whose oral health had some 279 impact on their daily activities. Adults and elderly individuals had the highest 
cumulative number of ODB components. 


\section{REFERENCES}

282 1. Peres MA, Macpherson LMD, Weyant RJ, Daly B, Venturelli R, Mathur MR, Listl

283 S, Celeste RK, Guarnizo-Herreño CC, Kearns C, Benzian H, Allison P, Watt RG.

284 Oral diseases: a global public health challenge. Lancet 2019; 394(10194):249-260.

285 Erratum in: Lancet. 2019 Sep 21;394(10203):1010.

286 2. Silva Junior MF, Sousa MDLR, Batista MJ. Reducing social inequalities in the oral 287 health of an adult population. Braz Oral Res 2020; 33:e102.

288 3. Boing AF, Bastos JL, Peres KG, Antunes JL, Peres MA. Social determinants of 289 health and dental caries in Brazil: a systematic review of the literature between 2901999 and 2010. Rev Bras Epidemiol 2014; 17(Suppl 2):102-115.

291 4. Pitts N, Amaechi B, Niederman R, Acevedo AM, Vianna R, Ganss C et al. Global 292 oral health inequalities: dental caries task group-research agenda. Adv Dent Res $2011 ; 23(2): 211-220$.

294

5. Sheiham A, Alexander D, Cohen L, Marinho V, Moysés S, Petersen PE, Spencer 295 J, Watt RG, Weyant R. Global oral health inequalities: task group_implementation and delivery of oral health strategies. Adv Dent Res 2011; 23(2):259-267.

297

6. Petersen PE, Bourgeois D, Ogawa H, Estupinan-Day S, Ndiaye C. The global 298 burden of oral diseases and risks to oral health. Bull World Health Org 2005; 83(9): 661-669.

7. Christensen LB, Twetman S, Sundby A. Oral health in children and adolescentes with different socio-cultural and socio-economic backgrounds. Acta Odontol Scand $2010 ; 68(1): 34-42$.

8. Molarius A, Engström S, Flink H, Simonsson B, Tegelberg A. Socioeconomic differences in self-rated oral health and dental care utilisation after the dental care reform in 2008 in Sweden. BMC Oral Health 2014; 14:134. 
9. Wallerstein N, Teórico Duran B. As raízes históricas e práticas do CBPR. In:

307 Pesquisa participativa comunitária em saúde: promoção da equidade social e da saúde. 3rd ed. São Francisco: Jossey-Bass, 2017.

10. Peres Neto J, Mendes KLC, Wada RS, Sousa MLR. Relação entre classificações de risco utilizadas para organização da demanda em saúde bucal em município de pequeno porte de São Paulo, Brasil. Ciênc. saúde coletiva 2017; 22(6): 1905-1911.

11. Arreaza ALV. Epidemiologia crítica: por uma práxis teórica do saber agir. Ciênc. saúde coletiva 2012; 17(4):1001-1013.

12. Machado FCA, Souza GCA, Noro LRA. Proposição de indicadores para vigilância da saúde bucal de adolescentes. Ciênc. saúde coletiva 2018; 23(1):187202.

13. Brasil. Lei 8.080 de 19 de setembro 1990. Dispõe sobre as condições para a promoção, proteção e recuperação da saúde, a organização e o funcionamento dos serviços correspondentes e dá outras providências. Diário Oficial da União 12 set 1990.

14. Watt RG, Daly B, Allison P, Macpherson LMD, Venturelli R, Listl S, Weyant RJ, Mathur MR, Guarnizo-Herreño CC, Celeste RK, Peres MA, Kearns C, Benzian H.

324 Ending the neglect of global oral health: time for radical action. Lancet 2019; 394(10194):261-272.

15. Kassebaum NJ, Smith AGC, Bernabé E, Fleming TD, Reynolds AE, Vos T,

327 Murray CJL, Marcenes W; GBD 2015 Oral Health Collaborators. Global, Regional, and National Prevalence, Incidence, and Disability-Adjusted Life Years for Oral

329 Conditions for 195 Countries, 1990-2015: A Systematic Analysis for the Global 330 Burden of Diseases, Injuries, and Risk Factors. J Dent Res 2017; 96(4):380-387. 
331

332

333

16. Matsuyama Y, Aida J, Tsuboya T, Hikichi H, Kondo K, Kawachi I, Osaka K. Are Lowered Socioeconomic Circumstances Causally Related to Tooth Loss? A Natural Experiment Involving the 2011 Great East Japan Earthquake. Am J Epidemiol 2017; 186(1):54-62.

17. Watt RG, Mathur MR, Aida J, Bönecker M, Venturelli R, Gansky SA. Oral health disparities in children. Pediatr Clin North Am 2018; 65:965-979.

18. SBSP 2015. https://w2.fop.unicamp.br/sbsp2015/. Accessed 24 Jun 2019.

19. Bulgareli JV, Faria ET, Cortellazzi KL, Guerra LM, Meneghim MC, Ambrosano GMB, Frias AC, Pereira AC. Factors influencing the impact of oral health on the daily activities of adolescents, adults and older adults. Rev Saude Publica 2018; $52: 44$

20. Gouvêa GR, Bulgareli JV, David LL, Ambrosano GMB, Cortellazzi KL, Guerra LM, Frias AC, Meneghim MC, Pereira AC. Variables associated with the oral impact on daily performance of adults in the state of São Paulo: A population-based study. PLoS One 2018; 13(9):e0203777.

21. Nogueira JS, Pereira AC, Frias AC, Ambrosano GMB, Cortellazzi KL, Guerra LM, Cavalcante DFB, Bulgareli JV. Social capital and factors associated with the caries experience in adults - a population-based study in Brazil. Braz Oral Res 2019; 20(33):e118.

22. Brito ACM, Bezerra IM, Cavalcante DFB, Pereira AC, Vieira V, Montezuma MF, Lucena EHG, Cavalcanti YW, Almeida LFD. Dental caries experience and associated factors in 12-year-old-children: a population based-study. Braz Oral Res 2020; 34:e010.

23. Cavalcanti YW, Almeida LFD, Lucena EHG, Probst LF, Cavalcante DFB, Frias AC, Bulgareli JV, Pereira AC. Factors that influence the oral impact on daily 
356 performance of older people in Brazil: A cross-sectional population-based study.

357 Gerodontology 2020; 37(1):78-86.

358 24. Cunha IP, Mialhe FL, Pereira AC, Vedovello SAS, Bulgareli JV, Frias AC, 359 Ambrosano GMB, de Castro Meneghim M. Self-perceived dental treatment need 360 among adolescents: A hierarchical analysis. Community Dent Oral Epidemiol 2020; 361 48(2):130-136.

362 25. Adulyanon S, Vourapukjaru J, Sheiham A. Oral impacts affecting daily 363 performance in a low dental disease Thai population. Community Dent Oral 364 Epidemiol 1996; 24(6):385-389.

365 26. Hongxing L, List T, Nilsson IM, Johansson A, Astrøm AN. Validity and reliability 366 of OIDP and OHIP-14: a survey of Chinese high school students. BMC Oral Health $367 \quad 2014 ; 14: 158$.

368 27. Infantosi AF, Costa JC, Almeida RM. Correspondence analysis: a theoretical 369 basis for categorical data interpretation in health sciences. Cad Saude Publica 2014; $370 \quad 30(3): 473-486$.

371 28. Arcaya MC, Arcaya AL, Subramanian SV. Inequalities in health: definitions, 372 concepts, and theories. Glob Health Action 2015; 8:27106.

373 29. Constante HM. Racial inequalities in public dental service utilization: Exploring 374 individual and contextual determinants among middle-aged Brazilian adults. 375 Community Dent Oral Epidemiol 2020; 00:1-7.

376 30. Pinheiro L, Fontoura NO, Querino AC, Bonetti A, Rosa W. Gender and Racial 377 Inequalities Profile. http://www.ipea.gov.br/retrato/indicadores.html. Accessed 24 378 Jun 2019. 
379 31. Chiavegatto Filho AD, Laurenti R. Racial/ethnic disparities in self-rated health: a multilevel analysis of 2,697 individuals in 145 Brazilian municipalities. Cad Saude Publica 2013; 29(8):1572-1582.

32. Celeste RK, Gonçalves LG, Faerstein E, Bastos JL. The role of potential mediators in racial inequalities in tooth loss: the Pró-Saúde study. Community Dent Oral Epidemiol 2013; 41(6):509-516.

33. Herkrath FJ, Vettore MV, Werneck GL. Contextual and individual factors associated with dental services utilisation by Brazilian adults: A multilevel analysis. PLoS One. 2018; 13(2):e0192771.

34. Watt RG, Sheiham A. Integrating the common risk factor approach into a social determinants framework. Community Dent Oral Epidemiol 2012; 40:289-296.

35. Aguiar VR, Pattussi MP, Celeste RK. The role of municipal public policies in oral health socioeconomic inequalities in Brazil: A multilevel study. Community Dent Oral Epidemiol 2018; 46(3):245-250.

36. Lahelma E, Martikainen P, Laaksonen M, Aittomäki A. Pathways between socioeconomic determinants of health. J Epidemiol Community Health 2004; 58(4):327-332.

37. Celeste RK, Eyjólfsdóttir HS, Lennartsson C, Fritzell J. Socioeconomic Life

Course Models and Oral Health: A Longitudinal Analysis. J Dent Res 2020; 99(3):257-263.

38. Locker D, Allen F. What do measures of 'oral health-related quality of life' 400 measure? Community Dent Oral Epidemiol 2007; 35(6):401-411.

401 39. Piovesan C, Antunes JL, Guedes RS, Ardenghi TM. Impact of socioeconomic and clinical factors on child oral health-related quality of life (COHRQoL). Qual Life

403 Res 2010; 19(9):1359-1366. 
404 40. Paula JS, Leite IC, Almeida AB, Ambrosano GM, Pereira AC, Mialhe FL. The 405 influence of oral health conditions, socioeconomic status and home environment 406 factors on schoolchildren's self-perception of quality of life. Health Qual Life 407 Outcomes 2012; 10:6.

408 41. Peres KG, Cascaes AM, Leão AT, Côrtes MI, Vettore MV. [Sociodemographic 409 and clinical aspects of quality of life related to oral health in adolescents]. Rev Saude 410 Publica 2013; 47(Suppl 3):19-28

411 42. Goes PSA, Moysés SJ. A utilização da informação para o planejamento e a 412 programação em saúde bucal. In: Goes PSA, Moysés SJ (Org.) Planejamento, 413 Gestão e Avaliação em Saúde Bucal. São Paulo: Artes Médicas; 2012. p. 55-70.

414 43. IBGE. Instituto Brasileiro de Geografia e Estatística. Estimativas da população 415 residente no brasil e unidades da federação com data de referência em $1^{\circ}$ de julho 416 de 2019. Disponível

em:

417 https://agenciadenoticias.ibge.gov.br/media/com mediaibge/arquivos/7d410669a4 418 ae85faf4e8c3a0a0c649c7.pdf. Acessed 10 April 2020. 
420 LIST OF ABBREVIATIONS

421 WHO - World Health Organization

422 SUS - Brazilian Unified Health System (Sistema Único de Saúde)

423 SBSP-2015 - Oral Health São Paulo 2015 (SB São Paulo 2015)

424 PSAs - Primary Stage Units

425 ODB - Oral Disease Burden

426 OIDP - Oral Impact on Daily Performance

427 PR - Prevalece Ratios

428 OR - Odds Ratios

429 MCA - Multiple Correspondence Analysis

$430 \mathrm{HRQOL}-$ Oral Health-Related Quality of Life 


\section{DECLARATIONS}

432

433

434

435

436

437

438

439

440

441

442

443

444

445

446

447

448

449

450

451

452

453
- Ethics approval and consent to participate

- Not applicable. As these are secondary data, there is no need for approval by the ethics committee. However, the Ethics Committee in Research of the Piracicaba Dental School, University of Campinas, certify that the project "Research in oral health state of São Paulo SB São Paulo 2015", register number 094/2015, of ANTONIO CARLOS PEREIRA, comply with the recommendations of the National Health Council - Ministry of Health of Brazil for research in human subjects and therefore was approved by this committee on August 02, 2015.

- Consent for publication

- Not applicable.

- Availability of data and materials

- The datasets analysed during the current study are available in the SBSP 2015, https://w2.fop.unicamp.br/sbsp2015/.

- Competing interests

- The authors declare that they have no competing interests.

- Funding

- Not Applicable.

- Authors' contributions

- Study concepts: EHGL, ROS, MLBR, ECFA, ACP e YWC; Study design: EHGL e YWC; Data acquisition: ROS, MLBR, ECFA; Data 
454

455

456

457

458

analysis and interpretation: EHGL; ACP e YWC; Statistical analysis:

YWC; Manuscript preparation, editing e review: EHGL, ROS, MLBR, ECFA, ACP e YWC..

- Acknowledgements

- Not Applicable. 


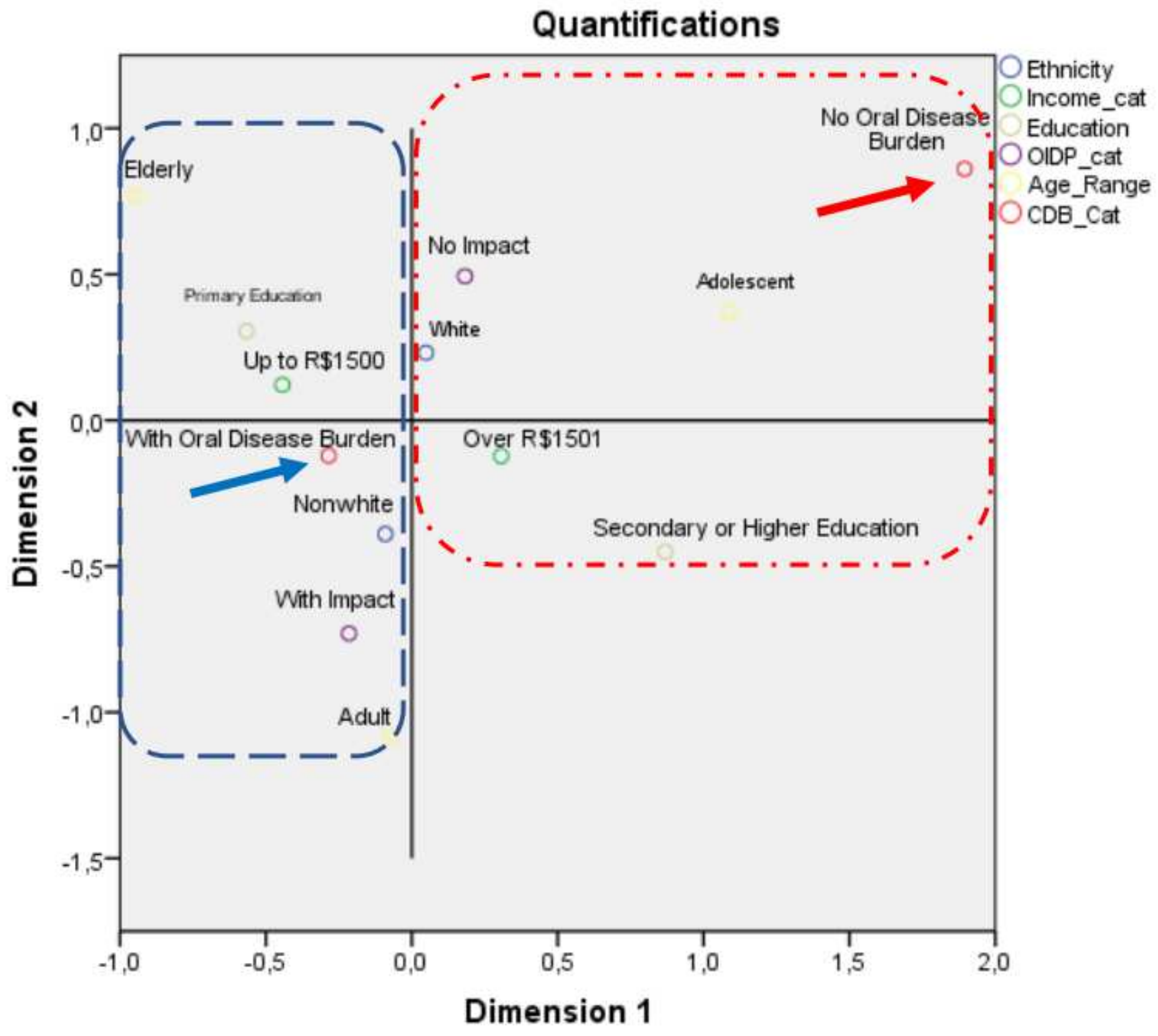

Figure 1

Multiple correspondence analysis for the categorical variables (ethnicity, family income, education, OIDP, age, and ODB).

\section{Supplementary Files}

This is a list of supplementary files associated with this preprint. Click to download. 
- Table2ArtigoCDBBMC.pdf

- Table1ArtigoCDBBMC.pdf

- Table3ArtigoCDBBMC.pdf 